\title{
Long-distance dispersal syndromes matter: diaspore-trait effect on shaping plant distribution across the Canary Islands
}

\author{
Yurena Arjona, Manuel Nogales, Ruben Heleno and Pablo Vargas \\ Y. Arjona (http://orcid.org/0000-0002-1851-1664) (yarjona@rjb.csic.es) and P. Vargas, Real Jardin Botánico (RJB-CSIC), Madrid, Spain. \\ YA also at: Univ. Rey Juan Carlos, Móstoles, Madrid, Spain. - M. Nogales, Island Ecology and Evolution Research Group (IPNA-CSIC), San \\ Cristóbal de La Laguna, Tenerife, Canary Islands, Spain. - R. Heleno (http:/lorcid.org/0000-0002-4808-4907), Centre for Functional Ecology, \\ Dept of Life Sciences, Univ. of Coimbra, Coimbra, Portugal.
}

\begin{abstract}
Oceanic islands emerge lifeless from the seafloor and are separated from continents by long stretches of sea. Consequently, all their species had to overcome this stringent dispersal filter, making these islands ideal systems to study the biogeographic implications of long-distance dispersal (LDD). It has long been established that the capacity of plants to reach new islands is determined by specific traits of their diaspores, historically called dispersal syndromes. However, recent work has questioned to what extent such dispersal-related traits effectively influence plant distribution between islands. Here we evaluated whether plants bearing dispersal syndromes related to LDD - i.e. anemochorous (structures that favour wind dispersal), thalassochorous (sea dispersal), endozoochorous (internal animal dispersal) and epizoochorous (external animal dispersal) syndromes - occupy a greater number of islands than those with unspecialized diaspores by virtue of their increased dispersal ability. We focused on the native flora of the lowland xeric communities of the Canary Islands (531 species) and on the archipelago distribution of the species. We controlled for several key factors likely to affect the role of LDD syndromes in inter-island colonization, namely: island geodynamic history, colonization time and phylogenetic relationships among species. Our results clearly show that species bearing LDD syndromes have a wider distribution than species with unspecialized diaspores. In particular, species with endozoochorous, epizoochorous and thalassochorous diaspore traits have significantly wider distributions across the Canary archipelago than species with unspecialized and anemochorous diaspores. All these findings offer strong support for a greater importance of LDD syndromes on shaping inter-island plant distribution in the Canary Islands than in some other archipelagos, such as Galápagos and Azores.
\end{abstract}

Colonization of new territories is a two-stage process defined by the arrival of organisms and the establishment of viable populations (MacArthur and Wilson 1967). Dispersal of organisms, particularly long-distance dispersal (LDD), is recognized as a key process that determines the arrival of colonizing propagules in remote territories and influences the composition of biological communities and species distribution (Carlquist 1981, Nathan 2006). This process is particularly critical for the colonization of oceanic islands - i.e. those that were never connected to continental landmasses (Gillespie and Clage 2009), and that therefore can only be colonized by species that successfully overcome long stretches of sea via LDD (MacArthur and Wilson 1967, Gillespie et al. 2012). For this reason, oceanic islands offer an ideal framework to study LDD processes in a biogeographical context (Vargas et al. 2012).

How plants reach these territories amidst the ocean has historically intrigued scientists (Darwin 1859, Ridley 1930). However, the low frequency of diaspore arrival makes this LDD process virtually impossible to observe (Higgins et al. 2003, Nathan 2006, Vargas 2007), hindering conclusions on the effectiveness of the different mechanisms involved in the dispersal of propagules to islands (Vargas et al. 2012). Indirect evidence is provided by dispersal syndromes (van der Pijl 1982), i.e. morphological traits of the diaspores that are related to the dispersal ability of plants and are therefore likely affecting their distribution (Ridley 1930, Higgins et al. 2003). Among all dispersal traits, only those associated with wind (anemochory), sea (thalassochory) and animal dispersal (endo- and epizoochory) could favour plant LDD to oceanic islands (Carlquist 1967). These morphological specializations related to particular dispersal vectors are known as LDD syndromes (Vargas et al. 2012). Traditionally, the dispersal vectors responsible for seed movements were directly inferred from the morphological traits of the diaspores, e.g. plant species with winged diaspores were assumed to have been transported long distances by wind. Those means of dispersal that match with the dispersal syndromes borne by the plant are known as standard means of dispersal (sensu Higgins et al. 2003). Nevertheless, recent studies have revealed that many plants with unspecialized diaspores have also successfully colonized remote territories (Vargas et al. 2014, Heleno and Vargas 2015), suggesting that non-standard means of 
dispersal play an important role in LDD (Higgins et al. 2003, Nogales et al. 2012). Due to the difficulty in making reliable inferences regarding the actual means of plant dispersal, a more objective approach to address LDD processes in colonization of oceanic islands is to assess whether species with particular dispersal syndromes have been favoured in the formation of insular floras (Vargas et al. 2012, Heleno and Vargas 2015). Leaving aside speculations about how plants reached islands, this new approach allows a probabilistic evaluation of the importance of the different LDD syndromes for island colonization.

In order to study the relationship between plant traits and their dispersal ability, most studies have focused on the colonization of archipelagos from the continental source floras (Jordan 2001, Vargas et al. 2012, Heleno and Vargas 2015). In this work we adopted a different approach, evaluating the colonization of different islands within a single archipelago, which can also provide valuable information regarding the effectiveness of LDD strategies (Vargas et al. 2014, Heleno and Vargas 2015). Although the distances are generally shorter than between continents and archipelagos, dispersal between islands is also considered LDD since diaspores have to cross significant sea barriers (Nathan 2006). Few studies addressed this intra-archipelago approach at the flora level, and primarily suggested only a very weak effect of the dispersal syndrome on plant distribution, contrary to what was expected. Among them, Vargas et al. (2014) detected only a small improvement on the colonization ability of thalassochorous plants in Galápagos over plants with any other dispersal syndromes, and Heleno and Vargas (2015) detected only a small advantage for endozoochorous diaspores in the Azores. In both archipelagos, plants with the other LDD syndromes did not seem to have any direct benefit regarding their colonization ability. It is thus still difficult to generalize the importance of dispersal traits for islands colonization, and the question remains as whether LDD syndromes affect plant distribution in other archipelagos.

The Canary Islands (northeast Atlantic Ocean) is an ancient volcanic archipelago (max. age ca $20 \mathrm{Myr}$; Whittaker and Fernández-Palacios 2007). This archipelago is made up of nine islands larger than $10 \mathrm{~km}^{2}$, and harbours 1333 native angiosperm species, mostly of Mediterranean origin. Several studies, albeit including single species, have focused on inter-island movements and colonization in the Canaries (García-Verdugo et al. 2010; Fernández-Mazuecos and Vargas 2011), but an overall analysis for the assemblage of the whole flora is still lacking. Clarifying the effect of LDD syndromes on plant distribution is intrinsically challenging, as there are many potential drivers that shape plant distribution patterns. This is particularly true in an ancient archipelago like the Canaries, where plant species ages are very heterogeneous. For example, the endemic Anagyris latifolia, diverged from its continental sister species ca. 8.20 Myr ago (Ortega-Olivencia et al. 2009), while the endemic Cistus horrens diverged much more recently, ca 0.29 Myr ago (Guzmán and Vargas 2010). This implies that, regardless of their dispersal potential, both species have had remarkably different time-windows and therefore, opportunities to colonize other islands within the archipelago. Geological changes are another important factor where alterations in sea level (eustasy) and erosion shaped the Canaries since their formation (Weigelt et al. 2016). Specifically, Fuerteventura, Lanzarote, La Graciosa, Alegranza and some islets were temporarily joined into the large palaeo-island called 'Mahan' during the Last Glacial Maximum (ca 20000 years ago; Rijsdijk et al. 2014). The presence of some plant species on these islands could therefore be the result of short-distance dispersal on land rather than LDD. It is thus vital to consider such factors to better understand the relevance of LDD syndromes in inter-island colonization. The well-known geological dates of individual island emergence and the numerous studies on the Canarian flora make this Atlantic archipelago an ideal scenario for a research on inter-island colonization.

In this paper, we test whether LDD syndromes have favoured wider plant species distributions across the Canary Islands, thus assessing the importance of diaspore traits in inter-island colonization within the archipelago (Vargas et al. 2014; Heleno and Vargas 2015). Importantly, we improved previous methodology by explicitly considering the geodynamics of the archipelago and the arrival time of plant species. Our working hypothesis is that angiosperm species with LDD syndromes (i.e. anemochorous, thalassochorous, endozoochorous and epizoochorous) have broader distributions, i.e. are present on more islands, than unspecialized plant species (Ridley 1930, van der Pijl 1982). Specifically, we address the following questions: 1) are species bearing LDD syndromes represented on more islands than plants with unspecialized diaspores? 2) which, if any, of the syndromes related to LDD were more successful in interisland colonization? 3) do the results vary when considering other factors that influence plant species distributions, such as the geodynamic history of the archipelago and species colonization time?

\section{Material and methods}

Our study was based on the following assumptions:

1) Once species arrived in the archipelago they had the same opportunity for inter-island colonization as those originated within the archipelago (Heleno and Vargas 2015).

2) All species had a single origin as long as there is no phylogenetic or phylogeographical evidence for multiple colonizations of the same species. When more than one lineage originated by different colonization events were detected for a single species, we considered them as statistically independent observations (Vargas et al. 2012, Heleno and Vargas 2015).

3) Endemic species have been in the archipelago for longer than non-endemic species (enough time for the accumulation of sufficient genetic changes for them be considered separate species; Vargas et al. 2012).

\section{The Canarian flora}

The Canary Islands are located in the Atlantic Ocean between $27-29^{\circ} \mathrm{N}$ and $13-18^{\circ} \mathrm{W}, 96 \mathrm{~km}$ off northwest Africa. Seven main islands (Lanzarote, Fuerteventura, 
Gran Canaria, Tenerife, La Gomera, El Hierro and La Palma), two smaller islands $\left(>10 \mathrm{~km}^{2}\right.$, La Graciosa and Alegranza) and several islets constitute this oceanic archipelago, whose oldest exposed rock emerged ca. 20 Myr ago (Whittaker and Fernández-Palacios 2007). The angiosperm flora comprises 1333 native species, about $40 \%$ of which are endemic (Acebes Ginovés et al. 2010). Acebes Ginovés et al. (2010) classified the native species into three groups expressing different degrees of their native-status certainty: 'certain natives' (including all endemics), 'likely natives' and 'suspected natives'. We analysed two groups: one including only certain-natives and the other formed by certain- and likely-natives. Species classifications depend on the floristic knowledge at a particular point in time; advances in this knowledge will thus introduce changes in the number of species as well as in their native status, so floristic lists should be used with caution (Schaefer et al. 2011). Indeed, more recent genetic data and phylogeographical reconstructions clearly support a native status for some Canarian plants such as Cistus monspeliensis (Fernández-Mazuecos and Vargas 2011) that were considered 'likely natives' (Acebes Ginovés et al. 2010). The aim of using different lists in our study was to assess the impact of the accuracy level on the native-status criteria in the analysis of diaspore syndrome and species distributions (Vargas et al. 2012). In order to assure that species distribution is determined by the arrival of diaspores rather than by the lack of suitable habitat available for recruitment, we only considered plant species occurring in the lowland xeric shrub communities, a habitat that can be found on all the islands studied (del Arco Aguilar 2006). Additionally, after reviewing the literature looking for evidence of multiple origins of these species we found that only Scrophularia arguta underwent at least three colonization events (Valtueña et al. 2016). Consequently, three independent lineages of $S$. arguta were included in the datasets as if they were independent species. As a result, we separately analysed 389 (hereafter 'certainnative' dataset) and 533 (hereafter 'certain-and-likelynative' dataset) lowland plant species.

\section{Dispersal syndrome assignment}

Species were categorized according to diaspore morphological traits related to LDD. We considered diaspores with structures that favour wind dispersal (wings, pappus) as having anemochorous traits; structures for floatability and survival in sea water (corky tissues, air chambers) as thalassochorous traits; fleshy and nutritive tissues attracting animal ingestion and dispersal as endozoochorous traits; and external animal dispersal structures (hooks, sticky substances) as epizoochorous traits (Vargas et al. 2012, 2014, Heleno and Vargas 2015). All the remaining species whose diaspores have no evident specialization towards LDD were classified as 'unspecialized'. This category includes plant species with syndromes limited to short distance dispersal, such as myrmecochory, autochory, as well as species without specific structures associated with dispersal, independent of their diaspore size (Heleno and Vargas 2015). Minute seeds were considered part of the unspecialized group unless they had morphological features directly related to LDD. Baseline information used for syndrome assignation was retrieved from plant and diaspore descriptions from published floras (Tutin et al. 1980, Castroviejo 1986-2012, Bramwell and Bramwell 2001), from the direct study of herbarium specimens and personal experimentation. This information was further cross-checked and complemented with information available from online databases (D ${ }^{3}$ : Hintze et al. 2013, SID: Royal Botantic Garden Kew 2017, Global Plants: JSTOR 2014). For a detailed guide of syndrome categorization see Appendix S1 in Heleno and Vargas (2015).

After syndrome assignment we found 17 and 27 species with more than one LDD syndrome (diplochorous species sensu Vargas et al. 2015) in certain-native and certain-andlikely-native datasets, respectively. These species represent only about $5 \%$ of the total in each case and were excluded from our analysis for simplicity. Finally, the total number of species considered was 372 in the certain-native dataset and 506 in the certain-and-likely-native dataset (Table 1).

\section{Species distribution}

The distribution of each species was estimated by the number of islands where the plant was found. In order to evaluate the potential effect of the geodynamic history of the archipelago, each species distribution was calculated in two ways, one based in the number of current islands occupied - those larger than $10 \mathrm{~km}^{2}$ (maximum of nine islands) and the other based on the number of palaeo-islands occupied (maximum of six palaeo-islands) (Fig. 1). Plant species distributions were obtained from the literature (Acebes Ginovés et al. 2010 for the seven main islands; Kunkel 1971 for Alegranza and La Graciosa).

Table 1. Number of Canary plant species bearing diaspores with different LDD syndromes analysed in this study (see main text). Proportions of endemic species included in each category are shown in brackets.

\begin{tabular}{|c|c|c|c|c|c|c|}
\hline & $\begin{array}{l}\text { No. of species } \\
(\% \text { endemics) }\end{array}$ & 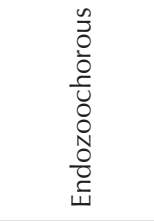 & 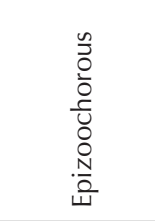 & 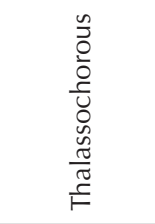 & 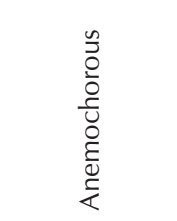 & 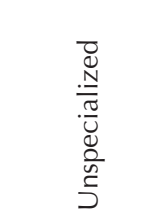 \\
\hline Certain-native species & 372 (71\%) & $21(42.9 \%)$ & 7 (14.3\%) & $21(19.1 \%)$ & $102(74.5 \%)$ & $221(78.7 \%)$ \\
\hline Certain-native and likely-native species & $506(52.2 \%)$ & $23(39.1 \%)$ & $19(5.3 \%)$ & $32(12.5 \%)$ & $123(61.8 \%)$ & $309(56.3 \%)$ \\
\hline
\end{tabular}

*Lowland species (see main text). 

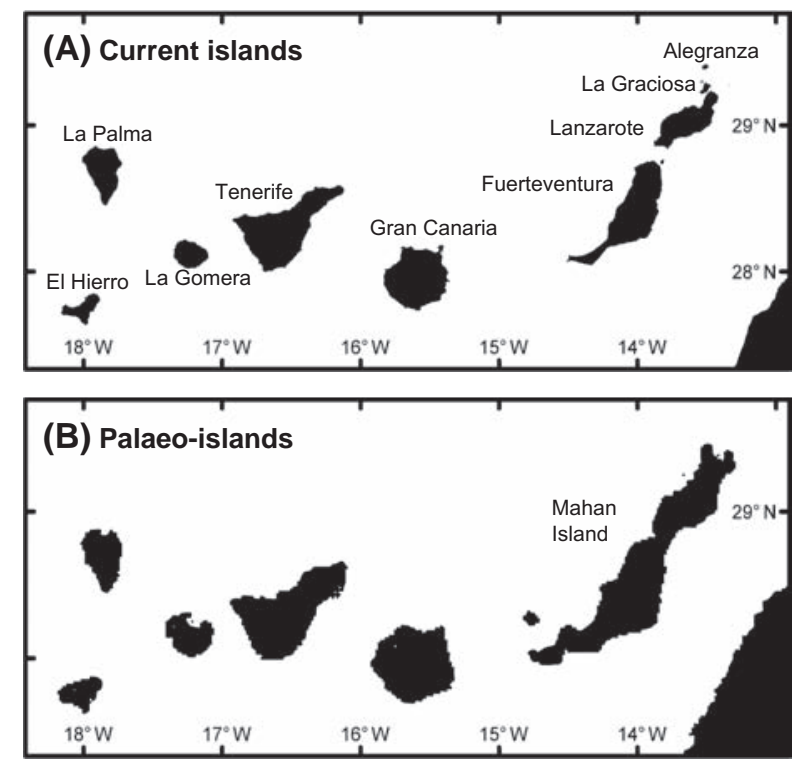

Figure 1. (A) The Canaries nowadays, formed by nine islands of more than $10 \mathrm{~km}^{2}$. (B) The Canaries at the Last Glacial Maximum (six palaeo-islands). Adapted with permission from Macmillan Publishers: Nature (Weigelt et al. 2016), copyright (2016).

\section{Time since colonization}

Two approaches were used to assess the effect of time-sincecolonization in the analyses: 1) species divergence time extracted from the literature; 2) the endemic status of each species as a proxy for the time that it has been present in the Canaries. For the first approach, we reviewed published time-calibrated phylogenies of Canarian lowland species and selected those species for which a divergence time from its sister taxon or group was available. All poorly resolved phylogenies were discarded, leaving a subset of 29 dated lowland species (Supplementary material Appendix 1 Table A1). For the second approach, we analysed the two species datasets considering the endemic status of each species as a proxy for the time they have been on the island, under the assumption that endemic species tend to have arrived earlier than non-endemic species.

\section{Statistical analyses}

The effect of LDD syndromes on plant distribution was evaluated using generalized linear models (GzLM). Two sets of models were fitted, for both of them the response variable was species distribution. However, the predictor variable was either a two-level categorical variable (with an LDD syndrome or not) or a five-level categorical variable defined by the morphological structures of the diaspore (endozoochorous, epizoochorous, anemochorous, thalassochorous, and unspecialized diaspores). The two models were run several times with some modifications to address the different factors, namely:

1. Geodynamic history (current islands vs palaeo-islands). The two models were run twice, each time considering distribution (response variable) as the number of current islands or palaeo-islands.
2. Native status effect (certain-native vs certain-and-likelynative datasets), using either of the two datasets.

3. Time effect (1). The models were repeated using a subset of species whose divergence time was obtained from the literature. A second predictor variable was included in the model; it was a two-level factor that groups the species into 'recent' (those that diverged during the Pleistocene, $<2.6 \mathrm{Myr}$ ) and 'old' species (that diverged before the Pleistocene, >2.6 Myr). The interaction of the two predictor variables was also considered. The aim was to test if older species are present on more islands than more recent ones and if this distribution is related to the species dispersal syndrome.

4. Time effect (2). For this approach, we included a second predictor variable 'endemicity' in the models, a categorical variable with two levels: endemic and non-endemic native, as proxies for ancient and recent colonization respectively. The interaction of the two predictor variables was also considered.

A Poisson distribution was used to deal with count data (number of islands) and whenever necessary over-dispersion in our models was corrected using the quasi-Poisson distribution for the error term. When an overall syndrome effect was found, pairwise comparison tests (Tukey test) were performed to detect the differing inter-island distributions of each dispersal syndrome. Because our data did not properly satisfy the canonical assumptions of GzLM, we recalculated all p-values based on a randomization method where the response variable was resampled randomly from the original dataset to rerun all models. This procedure was repeated 100000 times to produce a distribution of null-model (random) outcomes. We then compared the results of the model run with the observed data to the null-model frequency distribution, to determine the probability that these results were obtained by chance. The advantage of using a randomization method is that it creates its own frequency distribution, eliminating the assumptions of normality and homocedasticity (Manly 1991).

Finally, although each species was considered as a working unit, some of them belong to the same colonizing lineage that diversified in the archipelago, so not all the observations are independent. To test the influence of the phylogenetic relationship in the results we repeated the analyses including only single-species lineages. All analyses were performed and represented using packages car (Fox and Weisberg 2011), lsmeans (Lenth 2016), multcomp (Hothorn et al. 2008), RVAideMemoire (Hervé 2016) and ggplot2 (Wickham 2009) in $\mathrm{R}$ ver. 3.2.3 (R Core Team).

\section{Results}

\section{Dispersal syndrome effect on species distributions}

Plants with any of the LDD syndromes have significantly wider distributions across the Canary Islands than those with unspecialized diaspores $\left(\chi^{2}=11.39, \mathrm{df}=1, \mathrm{p}<0.001\right.$; Fig. 2A). We detected significant differences in the number 
(A)

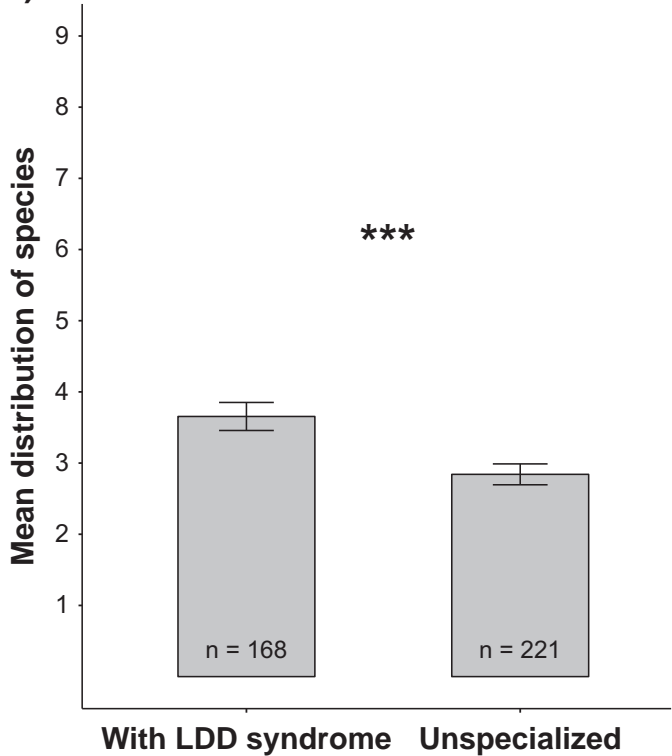

(B)

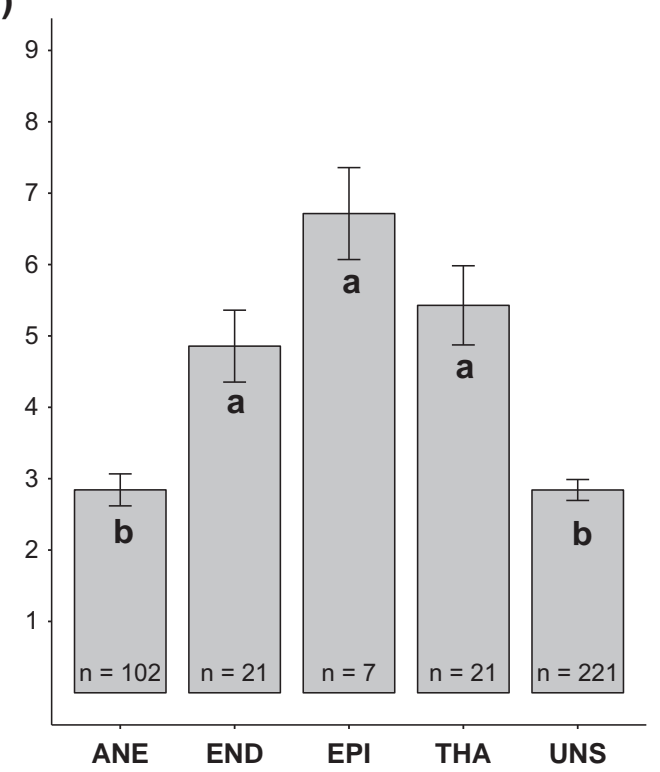

Figure 2. Mean distribution (number of current islands) of certain-native lowland species. (A) Distribution of species with and without LDD syndromes. The three asterisks indicate a statistically significant difference between groups $(\alpha=0.001)$. (B) Distribution of species with anemochorous (ANE), endozoochorous (END), epizoochorous (EPI), thalassochorous (THA) and unspecialized (UNS) diaspores. Letters indicate the results of the post-hoc comparison. Those groups with statistically supported differences (at $\alpha=0.05)$ are shown with different letters. Error bars indicate the standard error of the mean.

of islands (i.e. inter-island distribution) occupied by plants bearing different dispersal syndromes; specifically, plants with epizoochorous, endozoochorous and thalassochorous traits have significantly broader distributions than species with unspecialized or anemochorous diaspores (Fig. 2B and Supplementary material Appendix 2 Table A1).

\section{Incorporating geodynamics: nine current islands vs six palaeo-islands}

Models that considered plant distribution as the number of palaeo-islands where species are present gave similar results to those using the number of current islands. Species bearing a LDD syndrome are present on more palaeo-islands than unspecialized species $\left(\chi^{2}=10.06, \mathrm{df}=1, \mathrm{p}=0.002\right)$. Similarly, multiple comparison tests based on the distribution of plants across the six palaeo-islands also showed that endozoochorous, epizoochorous and thalassochorous species have wider distributions than those with anemochorous and unspecialized diaspores (Supplementary material Appendix 2 Table A1).

\section{Incorporating the effect of species native status certainty}

The overall syndrome effect in plant distribution did not differ when considering either only the certain-native plant species, or both all certain- (372 species) and likely-native (134 species) species altogether. In both analyses, plants with endozoochorous, epizoochorous and thalassochorous traits had broader distributions than those with anemochorous and unspecialized diaspores (Supplementary material Appendix 2 Table A1).

\section{Incorporating colonization time}

A review of the literature yielded divergence times for 29 lowland species (Supplementary material Appendix 1 Table A1), most of them endemic. Despite the reduced statistical power due to the small sample size, this data showed that older species $(>2.6 \mathrm{Myr})$ tend to occupy a larger number of islands than more recent species. Furthermore, we again detected that species with LDD syndromes have broader distributions than unspecialized species (Table 2A). Nevertheless, no significant interaction was detected between the age and the presence or absence of LDD syndromes $\left(\chi^{2}=0.03, \mathrm{df}=1\right.$, $\mathrm{p}=0.875)$ and hence it was not considered in the model for further analyses.

Results considering plant endemicity status as a proxy of species colonization time showed that plant distribution across the Canary Islands differed significantly between endemic and non-endemic plant species (Table $2 \mathrm{~B}$ ). In this case, endemic species show narrower geographic distributions than non-endemics $(2.42 \pm 1.95$ vs $4.99 \pm 2.32$ islands, respectively). LDD syndromes significantly influenced plant distribution as well; particularly, endozoochorous, epizoochorous and thalassochorous species have a broader distribution than unspecialized and anemochorous plants (Table 2B). Nevertheless, the analyses considering palaeoislands and certain-and-likely-native dataset revealed that only the endozoochorous and epizoochorous plants had wider distributions in most of the cases (Supplementary 
Table 2. Summary of multiple comparison Tukey post-hoc tests performed with the models that consider the influence of the following factors on the role of LDD syndromes in shaping plant distribution across the Canary Islands (measure as mean number of current islands occupied): (A) divergence time of a subset of 29 species obtained from the literature; (B) endemic status as a proxy of colonization time; and (C) phylogenetic relationships among species considering a single-species lineage subset of the certain-native dataset. Only the main effects of the predictor variables were considered. P-values were recalculated using randomization tests. The comparisons with significant differences at $\alpha=0.05$ are highlighted in bold. $\mathrm{END}=$ endozoochorous, $\mathrm{EPI}=$ epizoochorous, $\mathrm{ANE}=$ anemochorous,$\quad \mathrm{THA}=$ thalassochorous syndrome, UNS = unspecialized.

(A) Divergence time $(n=29)$

Model: mean number of current islands $\sim$ LDD + divergence time

\begin{tabular}{lcccc}
\hline & Estimate & SE & Z-value & $p$-value \\
\hline Without vs with LDD syndrome & -0.768 & 0.241 & -3.182 & $\mathbf{0 . 0 0 3}$ \\
Recent vs old species & -0.478 & 0.224 & -2.137 & $\mathbf{0 . 0 3 3}$ \\
\hline
\end{tabular}

(B) Endemic status $(n=372)$

Model: mean number of current islands $\sim$ syndrome + endemic status

\begin{tabular}{lrrrr}
\hline & Estimate & SE & Z-value & $p$-value \\
\hline END vs ANE & 0.326 & 0.138 & 2.361 & $\mathbf{0 . 0 1 1}$ \\
EPI vs ANE & 0.492 & 0.190 & 2.593 & $\mathbf{0 . 0 0 7}$ \\
THA vs ANE & 0.304 & 0.136 & 2.240 & $\mathbf{0 . 0 1 4}$ \\
UNS vs ANE & 0.031 & 0.084 & 0.371 & 0.355 \\
EPI vs END & 0.166 & 0.209 & 0.796 & 0.212 \\
THA vs END & -0.022 & 0.161 & -0.135 & 0.445 \\
UNS vs END & -0.295 & 0.129 & -2.282 & $\mathbf{0 . 0 1 4}$ \\
THA vs EPI & -0.188 & 0.205 & -0.919 & 0.180 \\
UNS vs EPI & -0.461 & 0.184 & -2.508 & $\mathbf{0 . 0 0 8}$ \\
UNS vs THA & -0.273 & 0.127 & -2.147 & $\mathbf{0 . 0 1 8}$ \\
Non-endemic vs endemic & 0.646 & 0.075 & 8.574 & $<\mathbf{0 . 0 0 1}$ \\
\hline
\end{tabular}

(C) Single-species lineages $(\mathrm{n}=132)$

Model: mean number of current islands $\sim$ syndrome

\begin{tabular}{lrrrr}
\hline & Estimate & SE & Z-value & p-value \\
\hline END vs ANE & 0.248 & 0.173 & 1.437 & 0.076 \\
EPI vs ANE & 0.510 & 0.190 & 2.680 & $\mathbf{0 . 0 0 4}$ \\
THA vs ANE & 0.322 & 0.154 & 2.092 & $\mathbf{0 . 0 1 9}$ \\
UNS vs ANE & -0.020 & 0.121 & -0.163 & 0.436 \\
EPI vs END & 0.262 & 0.216 & 1.213 & 0.115 \\
THA vs END & 0.074 & 0.185 & 0.399 & 0.347 \\
UNS vs END & -0.268 & 0.159 & -1.690 & $\mathbf{0 . 0 4 6}$ \\
THA vs EPI & -0.188 & 0.201 & -0.934 & 0.176 \\
UNS vs EPI & -0.530 & 0.178 & -2.983 & $\mathbf{0 . 0 0 1}$ \\
UNS vs THA & -0.342 & 0.138 & -2.477 & $\mathbf{0 . 0 0 8}$ \\
\hline
\end{tabular}

material Appendix 2 Table A2). The interaction of both predictor variables ('syndrome' and 'endemicity') was not significant $\left(\chi^{2}=4.45, \mathrm{df}=4, \mathrm{p}=0.349\right)$ and hence it was not considered in the model for further analyses.

\section{Independence of each observation: single-species lineages}

The analyses considering only monotypic lineages $(n=132)$ gave quite similar results. Endozoochorous and epizoochorous syndromes favour a broader plant distribution than unspecialized and anemochorous syndromes in all the cases (Supplementary material Appendix 2 Table A3). Thalassochorous plants have wider distributions than unspecialized and anemochorous species only when we considered the number of current islands as the response variable for the model and excluded likely-native species (Table 2C).

\section{Discussion}

Our analyses consistently revealed that Canary angiosperms bearing diaspores with traits related to endozoochory, epizoochory and thalassochory are more widely distributed among the islands of the archipelago than plant species with anemochorous or unspecialized diaspores. This result was not affected on considering the geodynamic history of the archipelago, or an expanded list that includes species whose native status is not completely certain (likely-natives). When using phylogenies to assess species relationships on the one hand, and endemicity data as a proxy of species time in the archipelago, on the other hand, the presence of animal dispersal syndromes continued to be significantly associated with broader distributions.

\section{Importance of dispersal syndromes for LDD}

Birds are frequently considered the main vector for transporting seeds to oceanic islands, either internally after ingestion, or externally adhered to their feet, feathers and beaks (Ridley 1930, Viana et al. 2016). This is coherent with our finding that plant species with endozoochorous and epizoochorous syndromes have been favoured in inter-island dispersal across the Canary archipelago (Fig. 2B). The importance of the endozoochorous syndrome in promoting the colonization of the Canaries by plants was already stressed by Bramwell (1985). Indeed, phylogenetic studies confirm that fleshy-fruited plants have been particularly successful in multiple colonization events from the continents to Macaronesia (Vargas 2007). Further examples show the role of endozoochorous traits favouring inter-island colonization within the Canaries (Olea, García-Verdugo et al. 2010) and Azores (Picconia, Ferreira et al. 2011; Juniperus, Rumeu et al. 2011a). These results are consistent with a recent meta-analysis in which fleshy fruits appear to have been related with wide inter-island distributions in several oceanic archipelagos (García-Verdugo et al. 2014). In comparison, the role of epizoochorous syndromes in favouring island colonization has been addressed less frequently (Sorensen 1986, Aoyama et al. 2012, Vazačová and Münzbergová 2014). Nevertheless, it has been shown that species without any specialization toward animal dispersal can also be effectively transported by them; this phenomenon is considered a non-standard mean of dispersal (Higgins et al. 2003, Nogales et al. 2012, Heleno et al. 2013a, b). Some examples of this are the transport of small seeds in mud attached on birds' feet (Darwin 1859, Ridley 1930), and the ingestion of unspecialized diaspores by granivorous birds (Heleno et al. 2011). Independently of the actual mean of plant dispersal, our results confirmed that species bearing diaspores with specializations promoting animal dispersal - i.e. fleshy pulp, bright colours and adhesion structures such as hooks or barbs - have had a clear and consistent advantage over unspecialized species in inter-island colonization. 
Plant species with sea-dispersal specializations tend to be associated with coastal habitats, and are often considered as important pioneers species in island colonization (Ridley 1930, Magnússon et al. 2014). Although sea currents can occasionally transport diaspores regardless of their specialization (e.g. in a raft), those able to float and survive long seawater immersion have clear advantages in colonizing oceanic islands (Higgins et al. 2003, Heleno and Vargas 2015). Significant inter-island colonization of the Canaries by plants with thalassochorous traits is supported by our results. Some Canary Island native species show an important potential for sea dispersal not only within but also between archipelagos as suggested by Romeiras et al. (2016) for Amaranthaceae species.

Wind has also been considered an important vector carrying propagules to remote archipelagos (Ridley 1930, Muñoz et al. 2004). However, Carlquist (1974) found that anemochorous traits have little importance in explaining species arrival from the continent to Hawai'i'. Indeed, the geographical and genetic isolation of island populations has been hypothesized to promote evolution towards loss of structures aiding aerial transport (e.g. pappus or plumose hairs) and larger diaspore sizes, and therefore a more limited dispersal ability (Carlquist 1974, Cody and Overton 1996, Kavanagh and Burns 2014). This may explain the significantly limited distribution of anemochorous species found in the present study (Fig. 2B). In contrast, Vazačová and Münzbergová (2014) found that certain species were better dispersed by wind to the youngest and westernmost island of the Canaries (El Hierro), although they found no relationship between dispersal traits and overall species distribution across the Canary Islands. Further research confirming the poor dispersal ability of anemochorous plants and disentangling the causes behind their limited distribution is necessary.

\section{Inter-island colonization patterns in different archipelagos}

Quantitative assessments of the importance of LDD syndromes on the distribution of island floras have been previously performed for the Galápagos (Vargas et al. 2014) and the Azores (Heleno and Vargas 2015). These two studies show some results similar to those of the present study. First, that a large fraction of the floras of these archipelagos presents unspecialized diaspores (Canaries 58\%, Galápagos 36\% and Azores 63\%). But also that: 1) anemochorous species have narrower distributions (although significant results have been found only in the Canary Islands), 2) thalassochorous species were highly effective in inter-island colonization of the Canaries and Galápagos, but not in Azores and 3) endozoochorous species have broader distributions than those without this syndrome on the three archipelagos (although this difference is only significant in the Canaries and the Azores).

Divergent results regarding the importance of LDD syndromes between archipelagos can be expected based on the archipelago-specific characteristics, such as age, area and isolation, different biotic interactions, and evolutionary histories. Nevertheless, the high percentage of unspecialized species found within each of these three archipelagos clearly points to the importance of non-standard dispersal events in current plant distribution (Nogales et al. 2012, Heleno and Vargas 2015).

\section{Additional factors affecting species distributions}

Species distributions are the result of ecological and evolutionary processes (Vellend and Orrock 2009). Speciation, extinction, island isolation, biotic interactions, island area, habitat suitability, human influence and time since arrival are some of the main factors that determine plant diversity and distribution within archipelagos (Patińo et al. 2017). Disentangling the importance of diaspore dispersal syndromes from among all these drivers remains an important challenge. Here, we performed several analyses in order to begin to elucidate the effects of some of these factors, namely habitat suitability (selecting a common habitat present on all islands), human influence (using only native species), time (considering species divergence times and comparing endemic vs non-endemic species), and the potential influence of phylogenetic relationships among species (single-species lineage analysis).

Species arrival time is likely an important factor influencing plant distribution. Our analyses of the 29 dated species resulted in wider distributions for older than more recent species (Table 2A). However, the analyses of the whole dataset showed that endemic species (that are assumed to be old) have narrower distributions than nonendemic species (assumed to be the result of recent colonizations) (Table 2B). These apparently contradictory results may be the consequence of factors other than the arrival time conditioning the endemic status of the species. Lack of LDD ability of the species favouring a genetic exchange between distant populations is one potential factor. In fact, anemochorous and unspecialized species - species with overall narrower distributions - were more numerous among endemic than non-endemic species (95\% vs 66\%, respectively). Interestingly, regarding endemic species, some of the most diverse plant genera in the archipelago are anemochorous or unspecialized, such as Sonchus (Kim et al. 1996), Echium (Garcia-Maroto et al. 2009), Lotus (Allan et al. 2004), Argyranthemum (Francisco-Ortega et al. 1997), Aeonium (Mort et al. 2002) and Sideritis (Barber et al. 2002). In contrast, most of the widespread endozoochorous endemic species belong to single-species lineages (e.g. Plocama pendula, Bosea yervamora and Dracunculus canariensis). In the light of our results, the different number of endemic species among lineages can also be explained by considering that species with lower dispersal abilities - i.e. anemochorous and unspecialized species - have limited distributions and are more prone to speciation than more successful species in inter-island colonization. Undoubtedly, further phylogenetic and phylogeographical research will continue to shed light on the interplay between dispersal ability and speciation (Carvajal-Endara et al. 2017). Nevertheless our results already suggest a significant effect of LDD syndromes on plant distribution, regardless of the colonization time, endemicity and phylogenetic relationships of the species. 


\section{Concluding remarks}

Our analysis of plant distribution and LDD syndromes suggests that diaspore traits, particularly those facilitating animal internal (endozoochory), animal external (epizoochory) and sea current dispersal (thalassochory) have played a historical role in promoting inter-island colonization across the Canary Islands. This effect remained significant even when controlling for other important factors that potentially affect plant distribution, such as past geodynamic processes in the archipelago, uncertainty in the species' native status, colonization time and phylogenetic relationships. Importantly, the Canaries show a much stronger and more consistent signal for the role of LDD syndromes than previously found for the Azores and Galápagos. On the other hand, the narrower distribution pattern of anemochorous species is consistent between the three archipelagos. Although other biotic and abiotic conditions are involved in the colonization process, these findings highlight the importance of diaspore specializations in LDD scenarios such as inter-islands dispersal. This encourages careful consideration of the multiple factors involved in the success of LDD, including dispersal syndromes of plant species which have been somewhat neglected in the recent literature.

Acknowledgements - We thank Paola Pérez, Diana Ínigo and Ana Otero for their collaboration with syndrome categorization, and Pedro Jordano and Nadir Alvarez for their advice. We also thank the subject editor Joaquín Hortal and two anonymous reviewers for their helpful comments and suggestions.

Funding - YA was financed by the Ministerio de Economía y Competitividad (Spain) (EEBB-I-15-10273). This study is framed within two projects regarding island colonization (CGL2012C02-01 and CGL2015-67865-P), also partially financed by Ministerio de Economía y Competitividad and the European Union. RH was supported by FCT grant IF/00441/2013 and Marie-Curie funding (CIG-321794).

\section{References}

Acebes Ginovés, J. R. et al. 2010. Pteridophyta, Spermatophyta. - In: Arechavaleta, M. et al. (eds), Lista de especies silvestres de Canarias (hongos, plantas y animales terrestres). Gobierno de Canarias, pp. 122-172.

Allan, G. J. et al. 2004. Molecular phylogenetic evidence for the geographic origin and classification of Canary Island Lotus (Fabaceae: Loteae). - Mol. Phylogenet. Evol. 32: 123-138.

Aoyama, Y. et al. 2012. Seabirds as adhesive seed dispersers of alien and native plants in the oceanic Ogasawara Islands, Japan. - Biodivers. Conserv. 21: 2787-2801.

Barber, J. C. et al. 2002. Origin of macaronesian Sideritis L. (Lamioideae: Lamiaceae) inferred from nuclear and chloroplast sequence datasets. - Mol. Phylogenet. Evol. 23: 293-306.

Bramwell, D. 1985. Contribución a la biogeografia de las Islas Canarias. - Bot. Macaronesica 14: 3-34.

Bramwell, D. and Bramwell, Z. 2001. Flores silvestres de las Islas Canarias. - Rueda.

Carlquist, S. 1967. The biota of long-distance dispersal. V. Plant dispersal to pacific islands. - Bull. Torrey Bot. Soc. 94: 129-162.

Carlquist, S. 1974. Island biology. - Columbia Univ. Press.

Carlquist, S. 1981. Chance dispersal: long-distance dispersal of organisms, widely accepted as a major cause of distribution patterns, poses challenging problems of analysis. - Am. Sci. 69: 509-516.

Carvajal-Endara, S. et al. 2017. Habitat filtering not dispersal limitation shapes oceanic island floras: species assembly of the Galápagos archipelago. - Ecol. Lett.: 1-10.

Castroviejo, S. (coord. gen.) 1986-2012. Flora iberica 1-8, 10-15, 17-18, 21. - Real Jardín Botánico, CSIC.

Cody, M. L. and Overton, J. M. 1996. Short-term evolution of reduced dispersal in island plant populations. - J. Ecol. 84: 53-61.

Darwin, C. 1859 . On the origin of species by means of natural selection, or the preservation of favoured races in the struggle for life. - John Murray.

del Arco Aguilar, M. J. 2006. Mapa de la vegetación de Canarias. - Grafcan, Santa Cruz de Tenerife.

Fernández-Mazuecos, M. and Vargas, P. 2011. Genetically depauperate in the continent but rich in oceanic islands: Cistus monspeliensis (Cistaceae) in the Canary Islands. - PLoS One 6: e17172.

Ferreira, R. C. et al. 2011. Phylogeography and conservation perspectives of an endangered macaronesian endemic: Picconia azorica (Tutin) Knobl. (Oleaceae). - Eur. J. For. Res. 130: $181-195$.

Fox, J. and Weisberg, S. 2011. An R companion to applied regression. - Sage.

Francisco-Ortega, J. et al. 1997. Molecular evidence for a Mediterranean origin of the Macaronesian endemic Argyranthemum (Asteraceae ). - Am. J. Bot. 84: 1595-1613.

Garcia-Maroto, F. et al. 2009. $\Delta 6$-Desaturase sequence evidence for explosive Pliocene radiations within the adaptive radiation of Macaronesian Echium (Boraginaceae). - Mol. Phylogenet. Evol. 52: 563-574.

García-Verdugo, C. et al. 2010. The relevance of gene flow in metapopulation dynamics of an oceanic island endemic, Olea Europaea subsp. guanchica. - Evolution 64: 3525-3536.

García-Verdugo, C. et al. 2014. Life history traits and patterns of diversification in oceanic archipelagos: a meta-analysis. - Bot. J. Linn. Soc. 174: 334-348.

Gillespie, R. M. and Clage, D. A. 2009. Encyclopedia of islands. - Univ. of California Press.

Gillespie, R. G. et al. 2012. Long-distance dispersal: a framework for hypothesis testing. - Trends Ecol. Evol. 27: 47-55.

Guzmán, B. and Vargas, P. 2010. Unexpected synchronous differentiation in Mediterranean and Canarian Cistus (Cistaceae). - Perspect. Plant Ecol. Evol. Syst. 12: 163-174.

Heleno, R. and Vargas, P. 2015. How do islands become green? - Global Ecol. Biogeogr. 24: 518-526.

Heleno, R. H. et al. 2011. The role of avian 'seed predators' as seed dispersers. - Ibis 153: 199-203.

Heleno, R. H. et al. 2013a. Seed dispersal networks in the Galápagos and the consequences of alien plant invasions. - Proc. R. Soc. B: 280: 20122112.

Heleno, R. H. et al. 2013b. Integration of exotic seeds into an Azorean seed dispersal network. - Biol. Invasions 15: 1143-1154.

Hervé, M. 2016. RVAideMemoire: diverse basic statistical and graphical functions. - R package ver. 0.9-54, < https://cran.rproject.org/web/packages/RVAideMemoire/index.html>.

Higgins, S. I. et al. 2003. Are long-distance dispersal events in plants usually caused by nonstandard means of dispersal? - Ecology 84: 1945-1956.

Hintze, C. et al. 2013. D3: the dispersal and diaspore database - baseline data and statistics on seed dispersal. - Perspect. Plant Ecol. Evol. Syst. 15: 180-192.

Hothorn, T. et al. 2008. Simultaneous inference in general parametric models. - Biom. J. 50: 346-363.

Jordan, G. J. 2001. An investigation of long-distance dispersal based on species native to both Tasmania and New Zealand. - Aust. J. Bot. 49: 333-340. 
JSTOR 2014. JSTOR Global Plants. - <https://plants.jstor. org/>.

Kavanagh, P. H. and Burns, K. C. 2014. The repeated evolution of large seeds on islands. - Proc. R. Soc. B 281: 20140675.

Kim, S. C. et al. 1996. A common origin for woody Sonchus and five related genera in the Macaronesian islands: molecular evidence for extensive radiation. - Proc. Natl Acad. Sci. USA 93: 7743-7748.

Kunkel, G. 1971. Vegetación de La Graciosa y notas sobre Alegranza, Montaña Clara y el Roque del Infierno. - Monogr. Biol. Canar. 2: 4-67.

Lenth, R. V. 2016. Least-squares means: the R package lsmeans. - J. Stat. Softw. 69: 1-33.

MacArthur, R. H. and Wilson, E. O. 1967. The theory of island biogeography. - Princeton Univ. Press.

Magnússon, B. et al. 2014. Plant colonization, succession and ecosystem development on Surtsey with reference to neighbouring islands. - Biogeosciences 11: 5521-5537.

Manly, B. F. J. 1991. Randomization and Monte Carlo methods in biology. - Chapman and Hall.

Mort, M. et al. 2002. Phylogenetics and evolution of the Macaronesian clade of Crassulaceae inferred from nuclear and chloroplast sequence data. - Syst. Bot. 27: 271-288.

Muñoz, J. et al. 2004. Wind as a long-distance dispersal vehicle in the southern hemisphere. - Science 304: 1144-1147.

Nathan, R. 2006. Long-distance dispersal of plants. - Science 313: 786-788.

Nogales, M. et al. 2012. Evidence for overlooked mechanisms of long-distance seed dispersal to and between oceanic islands. - New Phytol. 194: 313-317.

Ortega-Olivencia, A. et al. 2009. Systematics and evolutionary history of the circum-Mediterranean genus Anagyris L. (Fabaceae) based on morphological and molecular data. - Taxon 58: 1290-1306.

Patiño, J. et al. 2017. A roadmap for island biology: 50 fundamental questions after 50 years of the theory of island biogeography. - J. Biogeogr. 44: 963-983.

Ridley, H. N. 1930. The dispersal of plants throughout the world. - L. Reeve and Co.

Rijsdijk, K. F. et al. 2014. Quantifying surface-area changes of volcanic islands driven by Pleistocene sea-level cycles: biogeographical implications for the Macaronesian archipelagos. - J. Biogeogr. 41: 1242-1254.

Romeiras, M. M. et al. 2016. Evolutionary and biogeographic insights on the Macaronesian Beta-Patellifolia species (Amaranthaceae) from a time-scaled molecular phylogeny. - PLoS One 11: e0152456.

Supplementary material (Appendix ECOG-02624 at $<$ www. ecography.org/appendix/ecog-02624>). Appendix 1-2.
Royal Botanic Gardens Kew 2017. Seed information database (SID), ver. 7.1. - < http://data.kew.org/sid/>.

Rumeu, B. et al. 2011. The colonization history of Juniperus brevifolia (Cupressaceae) in the Azores islands. - PLoS One 6: e27697.

Schaefer, H. et al. 2011. The Linnean shortfall in oceanic island biogeography: a case study in the Azores. - J. Biogeogr. 38: 1345-1355.

Sorensen, A. E. 1986. Seed dispersal by adhesion. - Annu. Rev. Ecol. Evol. Syst. 17: 443-463.

Tutin, T. G. et al. 1980. Flora Europaea (Vol. I-V). - Cambridge Univ. Press.

Valtueña, F. J. et al. 2016. Scrophularia arguta, a widespread annual plant in the Canary Islands: a single recent colonization event or a more complex phylogeographic pattern? - Ecol. Evol. 6: 4258-4273.

van der Pijl, L. 1982. Principles of dispersal in higher plants. - Springer.

Vargas, P. 2007. Are Macaronesian islands refugia of relict plant lineages?: a molecular survey. - In: Weiss, S. and Ferrand, N. (eds), Phylogeography of southern European refugia. Springer, pp. 297-314.

Vargas, P. et al. 2012. Colonization of the Galápagos Islands by plants with no specific syndromes for long-distance dispersal: a new perspective. - Ecography 35: 33-43.

Vargas, P. et al. 2014. Plant colonization across the Galápagos Islands: success of the sea dispersal syndrome. - Bot. J. Linn. Soc. 174: 349-358.

Vargas, P. et al. 2015. Long-distance dispersal to oceanic islands : success of plants with multiple diaspore specializations. - AoB Plants 7: plv073.

Vazačová, K. and Münzbergová, Z. 2014. The importance of species traits for species distribution on oceanic islands. - PLoS One 9: e101046.

Vellend, M. and Orrock, J. L. 2009. Ecological and genetic models of diversity. - In: Losos, J. B. and Ricklefs, R. E. (eds), The theory of island biogeography revisited. Princeton Univ. Press, pp. 439-461.

Viana, D. S. et al. 2016. Migratory birds as global dispersal vectors. - Trends Ecol. Evol. 31: 763-775.

Weigelt, P. et al. 2016. Late Quaternary climate change shapes island biodiversity. - Nature 532: 99-102.

Whittaker, R. J. and Fernández-Palacios, J. M. 2007. Island biogeography: ecology, evolution, and conservation. - Oxford Univ. Press.

Wickham, H. 2009. ggplot2: elegant graphics for data analysis. - Springer. 